\title{
Membrane cholesterol depletion reduces breast tumor cell migration by a mechanism that involves non-canonical Wnt signaling and IL-10 secretion
}

Fabiana Sélos Guerra', Luzia da Silva Sampaio², Sandra Konig ${ }^{1}$, Martin Bonamino ${ }^{3,4}$, Maria Isabel Doria Rossi ${ }^{1}$, Manoel Luis Costa ${ }^{1}$, Patricia Fernandes ${ }^{1}$ and Claudia Mermelstein ${ }^{1 *}$

\begin{abstract}
Background: Migration and invasion are hallmarks of cancer cells that allow their dissemination to other tissues. Studying the cellular and molecular basis of cancer cell migration can help us to understand and control cancer metastasis. Many membrane molecules have been described as being involved in tumor cell migration, and among them is cholesterol.

Method: In the present study we investigated the role of membrane cholesterol in the migration of breast tumor cells. The human mammary gland/breast epithelial cell line MDA-MB 231 was used and membrane cholesterol was depleted with methyl- $\beta$-cyclodextrin (MbCD). Cell migration was measured in a cell-based scratch assay and the involvement of the Wnt signaling was tested using Lef-1/TCF reporter activation in permanently transfected MDA-MB 231 cells. Cell morphology was analyzed using fluorescent phalloidin to label F-actin structures.

Results: Our results show that membrane cholesterol depletion reduces cell migration, induces changes in cell morphology and in membrane protrusions. Cholesterol depletion also induces an increase in the secretion of IL-10, a cytokine involved in the control of cell migration. In addition, we show that these effects do not involve the activation of the canonical Wnt/beta-catenin pathway. Interestingly, Wnt5a inhibited cell migration in similar levels as $\mathrm{MbCD}$, pointing to a role for the non-canonical Wnt pathway and IL-10 in this process.

Conclusion: Taken together, our results suggest a correlation between membrane cholesterol, non-canonical Wnt signaling, IL-10 secretion and breast tumor cell migration. These results could contribute to the understanding of breast tumor cell migration and may be used in the development of new therapeutic strategies targeted to breast cancer metastasis.
\end{abstract}

Keywords: Cancer, Membrane cholesterol, Cell migration, IL-10, MDA-MB 231 cell line, Wnt pathway

\section{Background}

A breast tumor is composed of many different cells that are present in the inner and the outer region of the tumor mass. These cells are embedded in a complex extracellular matrix, which contains many soluble factors. A minority of these cells can undergo changes that enable then to migrate to a blood vessel and then to other tissues during the

\footnotetext{
* Correspondence: mermelstein@ufrj.br

${ }^{1}$ Instituto de Ciências Biomédicas, Universidade Federal do Rio de Janeiro,

Rio de Janeiro, RJ 21941-902, Brazil

Full list of author information is available at the end of the article
}

metastasis process. The molecules and the processes that can initiate and control tumor cell migration are poorly known. Understanding the molecular and cellular basis of breast cancer metastasis is crucial for the development of therapeutic strategies devoted to breast cancer treatment. A variety of membrane proteins and lipids have been implicated in the regulation of cancer cell adhesion and migration, and cholesterol in particular, has been related to several aspects of cancer pathology. Several studies support that cholesterol content in tumor cells is higher than in normal cells [1-5]. Transcriptional profiling by 
microarray has demonstrated that refractory cancers exhibit significant overexpression of a number of genes involved in the cholesterol biosynthetic pathway [6]. Cholesterol is an integral component of cellular membranes, determines membrane rigidity and fluidity, and plays a crucial role in membrane organization, dynamics, and function [7]. In the present study we investigated the possible role of membrane cholesterol in the regulation of tumor cell migration. We used the breast tumor cell line MDA-MB 231 to test the effects of cholesterol depletion on cell migration. To deplete cholesterol from the plasma membrane we used the substance methyl- $\beta$-cyclodextrin (MbCD), a compound that has a hydrophobic cavity with a high affinity for cholesterol $[8,9]$. In the last years our group has shown that cholesterol depletion induces the release of Wnt molecules, which in turn induces the proliferation and subsequent fusion of cultured skeletal muscle cells $[10,11]$. Here we show that cholesterol depletion from MDA-MB 231 cells result in a decrease in cell migration, which is accompanied by changes in cell morphology and by the secretion of IL10. The knowledge of the role of membrane cholesterol in the cellular response to migration could contribute to our understanding of tumor cell migration and may be used in the development of new therapeutic strategies targeted to breast cancer metastasis.

\section{Methods}

\section{Cell cultures}

This study using human cell lines was approved by the Ethics Committee for Animal Care and Use in Scientific Research from the Federal University of Rio de Janeiro. All cell culture reagents were purchased from Invitrogen (São Paulo, Brazil). The human mammary gland/breast epithelial cell line MDA-MB 231 was obtained from the American Type Culture Collection (ATCC ${ }^{\bullet}$ HTB-26 $6^{\mathrm{m}}$ ). Cells were routinely grown in RPMI medium containing $10 \%$ fetal bovine serum (FBS), $1 \%$ L-glutamine and $1 \%$ penicillin-streptomycin, in a humidified $5 \% \mathrm{CO}_{2}$ atmosphere at $37{ }^{\circ} \mathrm{C}$. Cells were cultured up to $70 \%-100 \%$ confluence and then some cultures were treated with the cholesterol depleting agent methyl- $\beta$-cyclodextrin (MbCD, Sigma, USA) at different concentrations for $2 \mathrm{~h}$. After MbCD treatment, cultures were washed with fresh cultured medium (RPMI with $2 \%$ FBS) and grown in culture medium with $2 \%$ FBS for the next 2 to $48 \mathrm{~h}$. Some cultures were grown in the presence of Wnt3a- or Wnt5aenriched medium, which was obtained respectively from mouse Wnt3a or Wnt5a transfected L-cells. Other cells were grown in the presence of the Wnt activator 6bromoindirubin-3'-oxime (Bio; Sigma) at a final concentration of $5 \mathrm{M}$ or with the Wnt inhibitor Dkk1 (recombinant mouse Dkk1 protein; R\&D Systems, USA) at a final concentration of $0.1 \mathrm{mg} / \mathrm{ml}$.

\section{Mouse L-cells culture and Wnt3a- and Wnt5a-conditioned medium preparation}

L-Wnt3a (ATCC ${ }^{\circ}$ CRL-2647 ${ }^{\mathrm{m}}$ ) and L-Wnt5a cells $\left(\right.$ ATCC $^{\circ}$ CRL-2814 ${ }^{\text {mix }}$ ) were cultured in DMEM supplemented with $10 \% \mathrm{FBS}$ and $0.4 \mathrm{mg} / \mathrm{ml}$ neomycin (Invitrogen) to maintain transgene expression during cell culture expansion. Conditioned medium from L-Wnt3a and from L-Wnt5a were collected as described below. Briefly, $1.3 \times 10^{6}$ cells were plated in $75 \mathrm{~cm}^{2}$ culture flasks with $14 \mathrm{ml}$ of medium without antibiotics, and left to grow for four days. The first batch of medium was collected and replaced with $14 \mathrm{ml}$ of fresh medium for another three days. The second batch of medium was then collected and the cells discarded. Both batches were mixed, sterile-filtered $(0.22 \mu \mathrm{m})$ and stored at $-20{ }^{\circ} \mathrm{C}$ for further assays.

\section{Cell viability assay}

Cell viability was determined using 3-(4,5-dimethyl-2-thiazyl)-2,5-diphenyl-2H-tetrazolium bromide (MTT) reagent (Sigma). Briefly, cells were plated at an initial density of $2.5 \times 10^{4}$ cells per well in 96-well plates and incubated for $24 \mathrm{~h}$ at $37{ }^{\circ} \mathrm{C}$ under $5 \% \mathrm{CO}_{2}$. Twenty-four-h cultures were treated with $\mathrm{MbCD}$ at a final concentration of 0.0001 , $0.001,0.01,0.1,0.5,1,2,5$ or $10 \mathrm{mM}$ for $2 \mathrm{~h}$. Cells treated with medium only (RPMI medium containing $10 \%$ FBS, $1 \%$ L-glutamine and $1 \%$ penicillin-streptomycin) served as a negative control group. After 24 or $48 \mathrm{~h}$ of treatment, the supernatant of each well was removed and cells were washed twice with PBS. Then, $10 \mu \mathrm{l}$ of MTT solution ( $5 \mathrm{mg} / \mathrm{ml}$ in PBS) and $100 \mu \mathrm{l}$ of medium were then added to each well and incubated for $4 \mathrm{~h}$ at $37{ }^{\circ} \mathrm{C}, 5 \% \mathrm{CO}_{2}$. The resultant formazan crystals were dissolved in dimethyl sulfoxide $(100 \mu \mathrm{l})$ and absorbance intensities were measured in a microplate reader (FlexStation 3 Reader, Molecular Devices, USA) at $570 \mathrm{~nm}$. All experiments were performed in triplicate, and the relative cell viability (\%) was expressed as a percentage relative to the untreated control cells.

\section{Trypan blue exclusion assay}

$\mathrm{MbCD}$ treated and non-treated cells were stained with $0.4 \%$ trypan blue, and then examined microscopically to determine the total number of cells and trypan blue positive cells. The ratio of trypan blue positive cells was calculated as following: [(the number of trypan blue positive cells)/(the number of total cells) $\times 100$.

\section{Plasma membrane integrity assay}

To measure plasma membrane integrity, we assayed serum lactate dehydrogenase (LDH) levels and calculated percentages of LDH release to the medium. LDH activity was measured spectrophotometrically using a commercial kit (Doles, Goiás, Brazil). After MbCD treatment, $50 \mu \mathrm{l}$ of the supernatant were transferred to an enzymatic assay 
plate and $50 \mu \mathrm{L}$ of $\mathrm{LDH}$ substrate plus $5 \mu \mathrm{L}$ ferric alumem were added and incubated for $3 \mathrm{~min}$ at $37{ }^{\circ} \mathrm{C}$, protected from light. Then, $10 \mu \mathrm{l}$ of NAD were added and absorbance intensities were measured in a microplate reader (FlexStation ${ }^{\circledR} 3$ Reader, Molecular Devices, USA) at $490 \mathrm{~nm}$. The percentage of LDH release was calculated by $([\mathrm{LDH}]$ sample $\times 100) /$ total $[\mathrm{LDH}] .[\mathrm{LDH}]$ sample was the $\mathrm{LDH}$ level of the sample (released in medium) and total [LDH] was the LDH content in the wells after addition of lysis solution (0.9\% Triton X-100).

\section{Lipid extraction and cholesterol determination}

The liquid culture media from untreated and MbCD treated cell cultures were collected after 2, 5, 8, 12, and $24 \mathrm{~h}$ after treatment for cholesterol determination. The extraction started by adding $4 \mathrm{ml}$ of chloroform:methanol: $\mathrm{HCl}(2: 1: 0.075, \mathrm{v} / \mathrm{v})$ and $1 \mathrm{ml}$ of $\mathrm{HCl} 0.6 \mathrm{M}$ to $1 \mathrm{ml}$ the samples in glass tubes, followed by agitation and centrifugation (10 min, $300 \mathrm{x} \mathrm{g}$ ). The organic phase (containing the lipids) was collected and $1 \mathrm{ml}$ of chloroform:methanol: $\mathrm{HCl}$ 0,6 M (3:48:47; v/v) was added, followed by agitation and centrifugation $(10 \mathrm{~min}, 300 \mathrm{x} g$ ). The final organic phase from each sample was dried under $\mathrm{N}_{2}$ gas and quantified gravimetrically. Cholesterol was determined according to the method described by Courchaine et al. [12]. Briefly, the dried lipids from each sample in duplicate were solubilized in $750 \mu \mathrm{l}$ of acetic acid, followed by the addition of $500 \mu \mathrm{l}$ of a color reagent $\left(0.05 \mathrm{~g} \mathrm{FeCl}_{3}\right.$, $2 \mathrm{ml} \mathrm{H}_{3} \mathrm{PO}_{4}, 23 \mathrm{ml} \mathrm{H}_{2} \mathrm{SO}_{4}$ ), vigorously homogenized in a vortex mixer, and kept for $10 \mathrm{~min}$ at room temperature. The absorbance of each sample was determined in a spectrophotometer (FlexStation ${ }^{\circledR} 3$ Reader, Molecular Devices, USA) at $550 \mathrm{~nm}$. Cholesterol (Sigma) was used as the standard. The results are expressed as mg cholesterol per $\mathrm{ml}$ of sample. Aliquots $(10 \mu \mathrm{l})$ from each sample were used for protein determination by BCA reagent (Thermo Scientific, USA), using bovine serum albumin as the standard.

\section{Cell-based scratch assay}

Cells were cultured in 24-well culture plates for $24 \mathrm{~h}$ up to $90 \%-100 \%$ confluence. Scratched wound lines on the upside of cultured cells were created by $200 \mu$ l yellow micropipette tip. The scratched cells were washed with PBS after removal of culture media. The cells were cultured for $2 \mathrm{~h}$ with $2 \mathrm{mM} \mathrm{MbCD}$ and after the removal of culture media cells were cultured for the next 2, 8, 12 or $24 \mathrm{~h}$. All cell-based scratch assays were performed in the presence of the anti-mitotic reagent cytosine arabinoside (ara-c; Sigma) at a final concentration of $10^{-5} \mathrm{M}$ in order to inhibit cell proliferation and analyze only cell migration. The wound area was measured from the image taken with an Axiovert 100 microscope (Carl Zeiss, Germany) by Image J program (NIH, USA) at 3 different sites from each wound area of gaps. Three independent experiments were performed.

\section{F-actin labeling}

Cells were rinsed with PBS and fixed with $4 \%$ paraformaldehyde in PBS for $10 \mathrm{~min}$ at room temperature. Cells were then permeabilized with $0.5 \%$ Triton-X 100 in PBS for $30 \mathrm{~min}$. Cells were then washed in PBS for $30 \mathrm{~min}$ and incubated with Texas Red Phalloidin (Molecular Probes, USA) for $1 \mathrm{~h}$ at $37{ }^{\circ} \mathrm{C}$. After incubation, cells were washed for $30 \mathrm{~min}$ with PBS. Nuclei were labeled with DAPI (4,6-Diamino-2-phenylindole dyhydrochloride; $0.1 \mu \mathrm{g} / \mathrm{ml}$ in $0.9 \% \mathrm{NaCl}$ ) for $5 \mathrm{~min}$. Cells were mounted in ProLong Gold antifade reagent (Molecular Probes) and examined with an Axiovert 100 microscope (Carl Zeiss, Germany). Images were acquired with an Olympus DP71 digital camera (Olympus, Japan).

\section{Cell electroporation and luciferase assay}

Electroporation was performed as previously described [13]. Briefly, $2 \times 10^{6} \mathrm{MDA}-\mathrm{MB} 231$ cells were ressuspended in $100 \mu \mathrm{l}$ of electroporation buffer $(5 \mathrm{mM} \mathrm{KCl}$; $15 \mathrm{mM} \mathrm{MgCl}$; $120 \mathrm{mM} \mathrm{Na} \mathrm{HPO}_{4} / \mathrm{NaH}_{2} \mathrm{PO}_{4} \mathrm{pH} 7.2$; $25 \mathrm{mM}$ Sodium Succinate; $25 \mathrm{mM}$ Manitol) containing $4 \mu \mathrm{g}$ of the reporter system plasmid 7xTcf-FFluc//SV40PuroR (7TFP, Addgene plasmid 24308) to evaluate the activation of Wnt signaling [14] and $0.4 \mu \mathrm{g}$ of TKRenilla plasmid (Promega, USA). The cells were immediately transferred to a sterile $0.2 \mathrm{~cm}$ cuvette (Mirus Biotech $^{\oplus}$, USA) and electroporated using the program X-013 of the Lonza $^{\circledR}$ Nucleofactor $^{\oplus}$ II electroporation system. After electroporation, cells were plated in 12-well plates at an initial density of $10^{5}$ cells/well and left to adhere overnight at $37{ }^{\circ} \mathrm{C}$ and $5 \% \mathrm{CO}_{2}$. On the following day, cultures were rinsed with PBS and incubated in triplicates with $2 \mathrm{mM} \mathrm{MbCD}, 10 \% \mathrm{Wnt} 3 \mathrm{a}$-medium or $5 \mu \mathrm{M}$ Bio for $24 \mathrm{~h}$. Cells were lysed with $80 \mu \mathrm{l}$ of Reporter Lysis buffer/well (Promega, USA) and processed to a single freeze/thaw cycle at $-80{ }^{\circ} \mathrm{C}$ to achieve complete lysis. After a brief centrifugation at $4{ }^{\circ} \mathrm{C}$, supernatants were used to quantify luciferase activity through light detection by luminometer (Glomax, Promega, USA) after adding the Luciferase Assay Reagent according to the manufacture's protocol.

\section{ELISA}

The levels of IL-10 in cultured media were determined by enzyme-linked immunosorbent assay (ELISA) protocol as standardized by BD Biosciences (USA). Conditioned media were collected from untreated cultures and after 2 , 8 and $24 \mathrm{~h}$ of treatment with $2 \mathrm{mM} \mathrm{MbCD}$ or $10 \%$ Wnt3a or $10 \%$ Wnt5a. Samples were centrifuged and the supernatants used for measurement of the concentration of IL-10. Briefly, the anti-mouse IL-10 capture monoclonal 
antibody $(2 \mu \mathrm{g} / \mathrm{ml}$, R\&D Systems, USA) was absorbed on a polystyrene 96-well plate (Maxisorb, NUNC, Denmark), and the IL-10 present in the sample was bound to the antibody-coated wells. The recombinant mouse IL-10 (16 pg/ml to $0.125 \mathrm{pg} / \mathrm{ml}, \mathrm{R} \& D$ Systems, USA) was added to standard wells. The biotinylated anti-mouse IL-10 detecting $\mathrm{mAb}(0.1 \mu \mathrm{g} / \mathrm{ml}, \mathrm{R} \& \mathrm{D}$ Systems, USA) was added to bind the IL-10 captured by the first antibody. After washing, streptavidin-horseradish peroxidase (streptavidin-HRP, Zymed, USA) was added to the wells to detect the biotinylated detecting antibody, and finally a Tetramethyl Benzidine chromogenic solution (TMB, Zymed) was added as a substrate, and a colored product formed in proportion to the amount of IL-10 present in the samples was stopped with $\mathrm{HCl} 1 \mathrm{~N}$. Absorbance was read using $450 \mathrm{~nm}$ as wavelength. All samples were analyzed in duplicate. Results of cytokine concentration were expressed in $\mathrm{pg} / \mathrm{ml}$ and were mean of three different experiments.

\section{Statistical analysis}

All the values were represented as the mean \pm standard error. Statistical analysis was performed with one-way ANOVA on Ranks with Newman-Keuls Post Hoc test and statistical significance was defined as ${ }^{*} p<0.05$ and $* * 0<0.001$.

\section{Results and Discussion}

To study the role of membrane cholesterol during the migration of the breast tumor cell line MDA-MB 231, we depleted cholesterol with the substance methyl- $\beta$ cyclodextrin (MbCD). MbCD can selectively exclude cholesterol from cell membranes [15] and thus it is presumed to change the membrane composition and structure, particularly the cholesterol-enriched membrane microdomains. First, we analyzed the viability of the cells after 24 and $48 \mathrm{~h}$ of treatment with different concentration of $\mathrm{MbCD}$ (from 0.0001 to $10 \mathrm{mM}$ for $2 \mathrm{~h}$ ). The results of the MTT assay show that 0.0001 to $5 \mathrm{mM}$ of $\mathrm{MbCD}$ did not alter cell viability, but $10 \mathrm{mM}$ of $\mathrm{MbCD}$ reduced cell viability (Fig. 1a). We also analyzed the plasma membrane integrity by measuring the serum lactate dehydrogenase (LDH) levels in the culture medium. Our data show that from 0.0001 to $5 \mathrm{mM}$ of $\mathrm{MbCD}$ did not change LDH levels, but $10 \mathrm{mM}$ of $\mathrm{MbCD}$ induced an increase in the levels of LDH (Fig. 1b). In addition, trypan blue exclusion assay showed that only 5 and $10 \mathrm{mM}$ of $\mathrm{MbCD}$ induced a decrease in the percentage of viable cells (Fig. 1c). In agreement with our results, Onodera and colleagues [16] have shown that $20 \mathrm{mM}$ $\mathrm{MbCD}$ (for $2 \mathrm{~h}$ ) induces apoptosis in different tumor cell lines. In conclusion, our results from cell viability (MTT), plasma membrane integrity (LDH) and trypan blue exclusion assays show that treatment of cells for $2 \mathrm{~h}$ with up to $2 \mathrm{mM}$ of $\mathrm{MbCD}$ did not alter cell

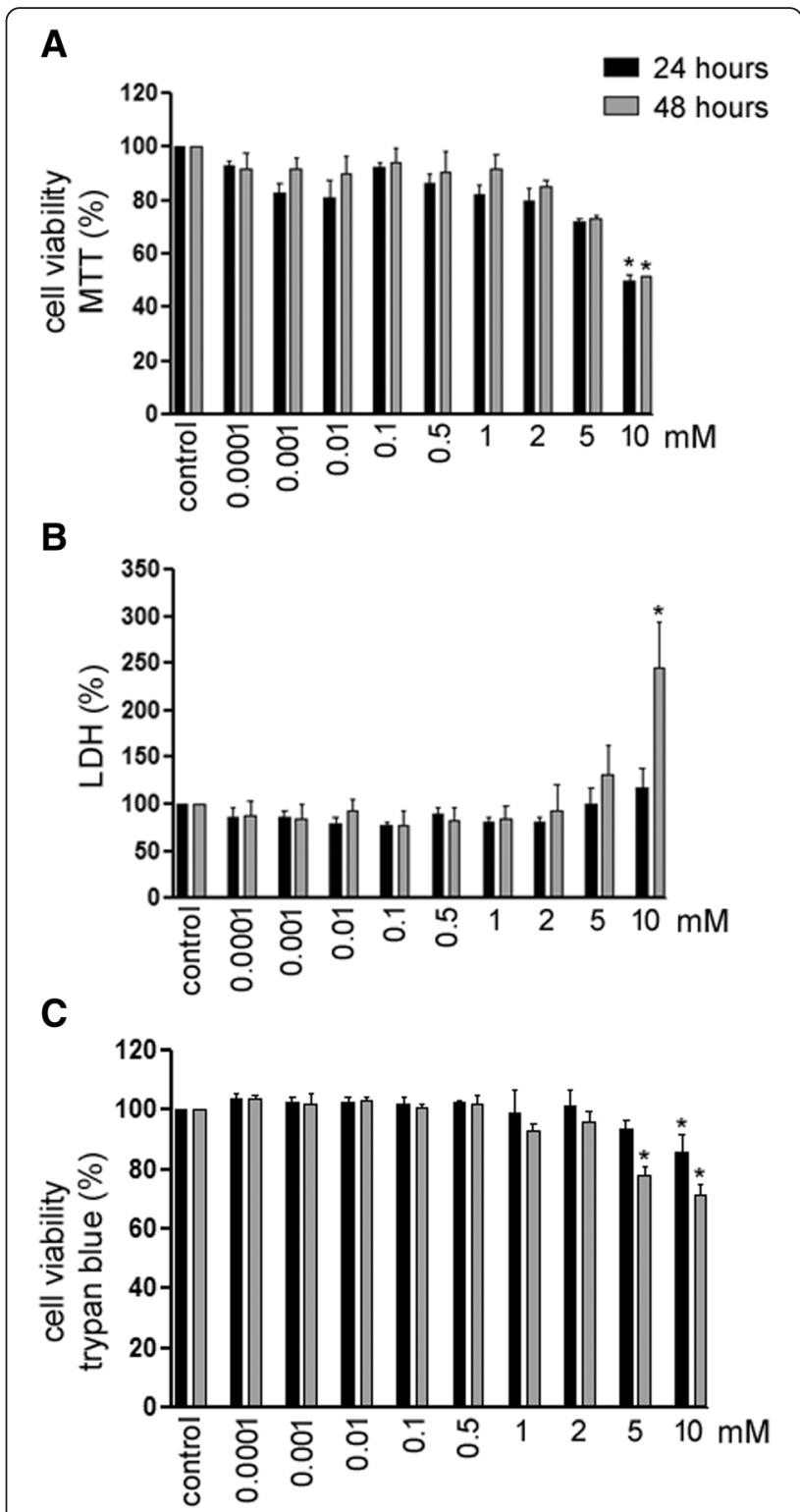

Fig. 1 Cell viability analysis after MbCD-induced cholesterol depletion in MDA-MB 231 cells. (a) A MTT-based method was used to analyze cell viability in untreated and $\mathrm{MbCD}$-treated cells. A significant decrease in cell viability was observed $24 \mathrm{~h}$ and $48 \mathrm{~h}$ after treatment of cells with $10 \mathrm{mM}$ of MbCD. MbCD treatment in the range between 0.0001 to 5 $\mathrm{mM}$ showed no effect on cell viability. (b) Measurements the serum lactate dehydrogenase ( $(\mathrm{DH})$ levels in the culture medium were performed to analyze plasma membrane integrity. MbCD treatment in the range between 0.0001 to $5 \mathrm{mM}$ of MbCD did not change LDH levels, but $10 \mathrm{mM}$ of $\mathrm{MbCD}$ induced an increase in the levels of $\mathrm{LDH}$ after $48 \mathrm{~h}$ of treatment. (c) Trypan blue exclusion assay was used to analyze the number of viable cells. MbCD treatment in the range between 0.0001 to $2 \mathrm{mM}$ of MbCD did not change LDH levels, but 5 and $10 \mathrm{mM}$ of MbCD induced a decrease in the percentage of viable cells after $24 \mathrm{~h}$ (only for $10 \mathrm{mM}$ ) and $48 \mathrm{~h}$ of treatment. Each bar represents the mean and standard error of 3 independent experiments. ${ }^{*} p<0.05$; ANOVA versus control group 
viability, whereas concentrations above $5 \mathrm{mM}$ reduce cell viability. Consistent with these results, our group has previously shown that $2 \mathrm{mM}$ of MbCD do not interfere with cell viability in skeletal and cardiac muscle cells grown in vitro $[17,18]$.

Then, we wanted to confirm the efficiency of MbCD to induce cholesterol depletion in the membrane of MDA-MB 231 cells. For this purpose, we estimated the amount of cholesterol released in the culture media of control and MbCD-treated cultures. Our results show a 3 -fold increase in cholesterol concentration in the liquid culture medium during the 2 -h treatment with $2 \mathrm{mM}$ MbCD (Fig. 2a). After changing the medium containing $\mathrm{MbCD}$ for a fresh one without the drug ( $5 \mathrm{~h}$ after MbCD

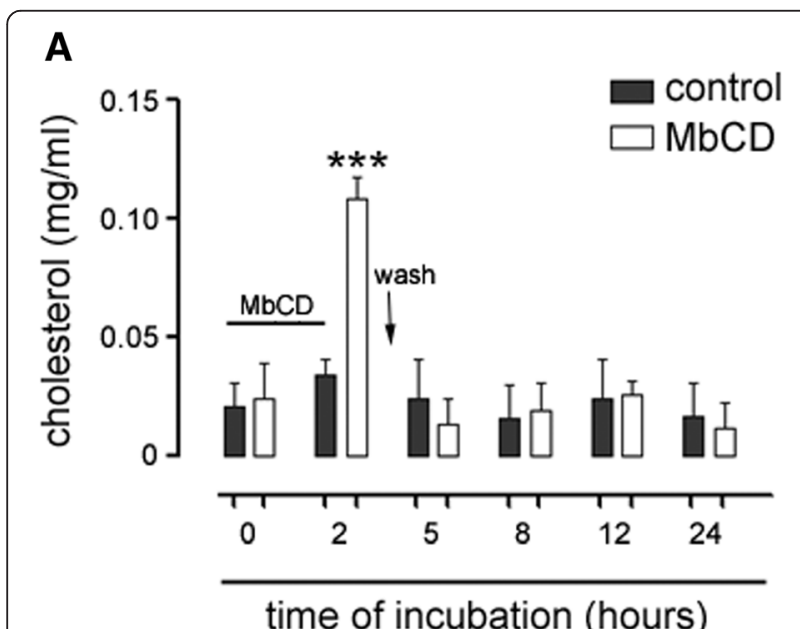

B

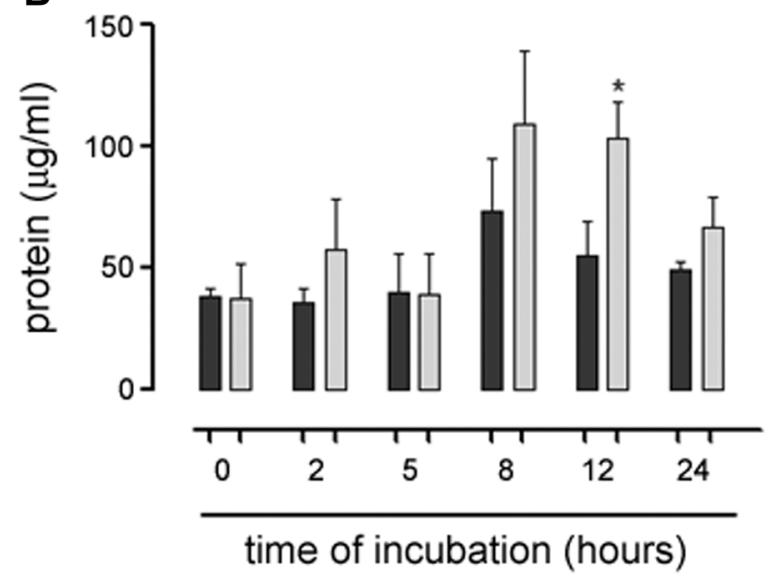

Fig. 2 Levels of cholesterol and proteins are enhanced in the cultured media following treatment with MbCD in MDA-MB 231 cells. (a and b) The amount of cholesterol and proteins was estimated in the following conditions: growth medium immediately before $\mathrm{MbCD}$ treatment $(0 \mathrm{~h})$ and at the end of MbCD treatment (2 h), as well as at 5, 8, 12 or $24 \mathrm{~h}$ after treatment. Note a high increase in the amount of cholesterol present in the culture medium only after $2 \mathrm{~h}$ of MbCD treatment, and an increase in total protein levels only after $12 \mathrm{~h}$ of treatment. Each bar represents the mean and standard error of 3 independent experiments. ${ }^{*} p<0.05$ and ${ }^{* *} p<0.001$; ANOVA versus control group (0 hs) treatment in Fig. 2a), the levels of cholesterol in the liquid medium returned to values similar to the ones found before MbCD treatment.

It has been demonstrated that $\mathrm{MbCD}$ extracts not only cholesterol from plasma membranes, but also membrane proteins [8]. So, we decided to analyze the amount of proteins present in the $\mathrm{MbCD}$-conditioned media. We found a significant increase in the amount of proteins in the conditioned media collected $12 \mathrm{~h}$ after MbCD treatment (Fig. 2b), when compared to conditioned media collected from untreated cultures (control). These data suggest that MbCD induces the release and/or secretion of proteins from the cells to the culture media. These results are in agreement with our previous work showing that $\mathrm{MbCD}$ induces the release of proteins in cultured cells [11].

Since we found that treatment of MDA-MB 231 cells with $2 \mathrm{mM}$ of $\mathrm{MbCD}$ for $2 \mathrm{~h}$ was able to remove high levels of cellular cholesterol without interfering with cell viability (Figs. 1 and 2), we decided to use this concentration of $\mathrm{MbCD}$ and duration of treatment for all the subsequent experiments in order to deplete membrane cholesterol and analyze its effects in cell migration.

Interestingly, we found that $\mathrm{MbCD}$ induces changes in cell morphology. At the border of the scratched areas of the culture dish, control cells displayed many ruffled membranes and lamellipodia whereas in cholesterol depleted cells membrane protrusions were less prominent and most of the cells displayed a spindle shaped morphology (Figs. 3 and 4). These differences are clearly observed when cells were labeled with Phalloidin, which stains filamentous actin (Figs. 3 and 4). Membrane protrusions areas, such as ruffled membranes, lamellipodia and filopodia, are usually filled with actin filaments, which are known to interact with the plasma membrane. Our results suggest that $\mathrm{MbCD}$-induced cholesterol depletion inhibits the formation and/or induces the retraction of membrane protrusions. We also found that cholesterol depleted cells were less spread in the culture dish and displayed an increase in the Z-axis as compared to control cells (Fig. 4).

Next, we analyzed the effects of cholesterol depletion in the migration of MDA-MB 231 cells. Cells were cultured up to $90 \%-100 \%$ confluence and then scratched wound lines were created by a micropipette tip. Some of the scratched cultures were treated for $2 \mathrm{~h}$ with $2 \mathrm{mM}$ $\mathrm{MbCD}$ and then the culture media was removed and cells were cultured for the next 8 or $24 \mathrm{~h}$ in fresh media (without MbCD). Interestingly, untreated cells completely covered the scratched areas of the dish after $24 \mathrm{~h}$ of culture while in MbCD-treated cultures it is possible to see a relatively large empty area in the culture dish after $24 \mathrm{~h}$ of treatment (Fig. 5). Quantification of the shaved area showed that $60 \%$ of the scratched area was 

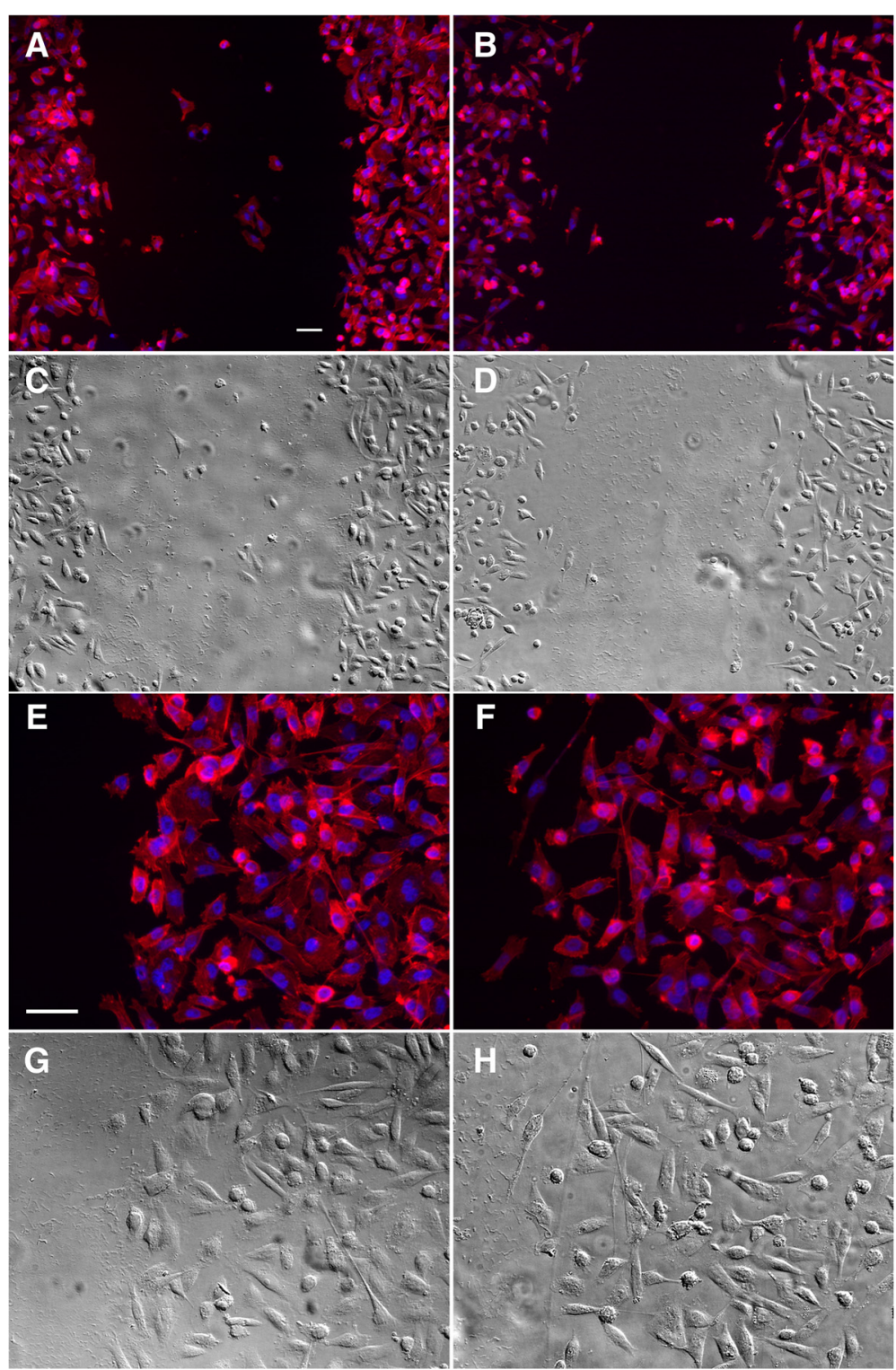

Fig. 3 Cholesterol depletion induces changes in cell morphology and in the distribution of actin filaments. MDA-MB 231 cells were grown for $24 \mathrm{~h}$, scratched wound lines were created and cultures were treated with MbCD (b, d, $\mathbf{f}, \mathbf{h})$. Some cells were not treated (control, $\mathbf{a}, \mathbf{c}, \mathbf{e}, \mathbf{g})$. Cells were analyzed $2 \mathrm{~h}$ after MbCD treatment by staining with the F-actin probe Texas red-Phalloidin (red, $\mathbf{a}, \mathbf{b}, \mathbf{e}, \mathbf{f}$ ) and the nuclear stain Dapi (blue, $\mathbf{a}, \mathbf{b}, \mathbf{e}, \mathbf{f})$ and by phase contrast microscopy $(\mathbf{c}, \mathbf{d}, \mathbf{g}, \mathbf{h})$. Merged images shown with Phalloidin/Dapi labeling $(\mathbf{a}, \mathbf{b}, \mathbf{e}, \mathbf{f})$ are the same microscopic fields as the ones shown under phase contrast microscopy $(\mathbf{c}, \mathbf{d}, \mathbf{g}, \mathbf{h})$. While the scratched area can be better appreciated on the low magnification (a-d), the higher magnification images (e-h) illustrate more clearly the overall cell morphology. Note that control cells (a, $\mathbf{c}, \mathbf{e}, \mathbf{g})$ display many ruffled membranes and lamellipodia whereas in cholesterol depleted cells $(\mathbf{b}, \mathbf{d}, \mathbf{f}, \mathbf{h})$ membrane protusions were less prominent and most of the cells are spindle-shaped. Scale bar in A represent $50 \mu \mathrm{m}$ in (a-d), and scale bar in E represents $50 \mu \mathrm{m}$ in (e-h)

still empty after $24 \mathrm{~h}$ of MbCD treatment (Fig. 6). The collection of these data shows that MbCD-induced cholesterol depletion inhibits cell migration in MDA-MB 231 cells. These results are in agreement with previous observations that cholesterol or high-density lipoprotein (HDL) treatments are able to stimulate MDA-MB 231 cell migration $[19,20]$ and with data showing that MDA-MB-231 cells grown in lipid-depleted medium resulted in an $85 \%$ decrease in cell migration [21]. Raghu and colleagues [22] showed that $10 \mathrm{mM} \mathrm{MbCD}$ inhibited the migration of MDA-MB 231 cells with no interference in cell viability.

In the last years our group has shown that membrane cholesterol depletion induces the release of Wnt molecules to the culture medium, which in turn induces the proliferation and differentiation of cultured skeletal muscle cells 

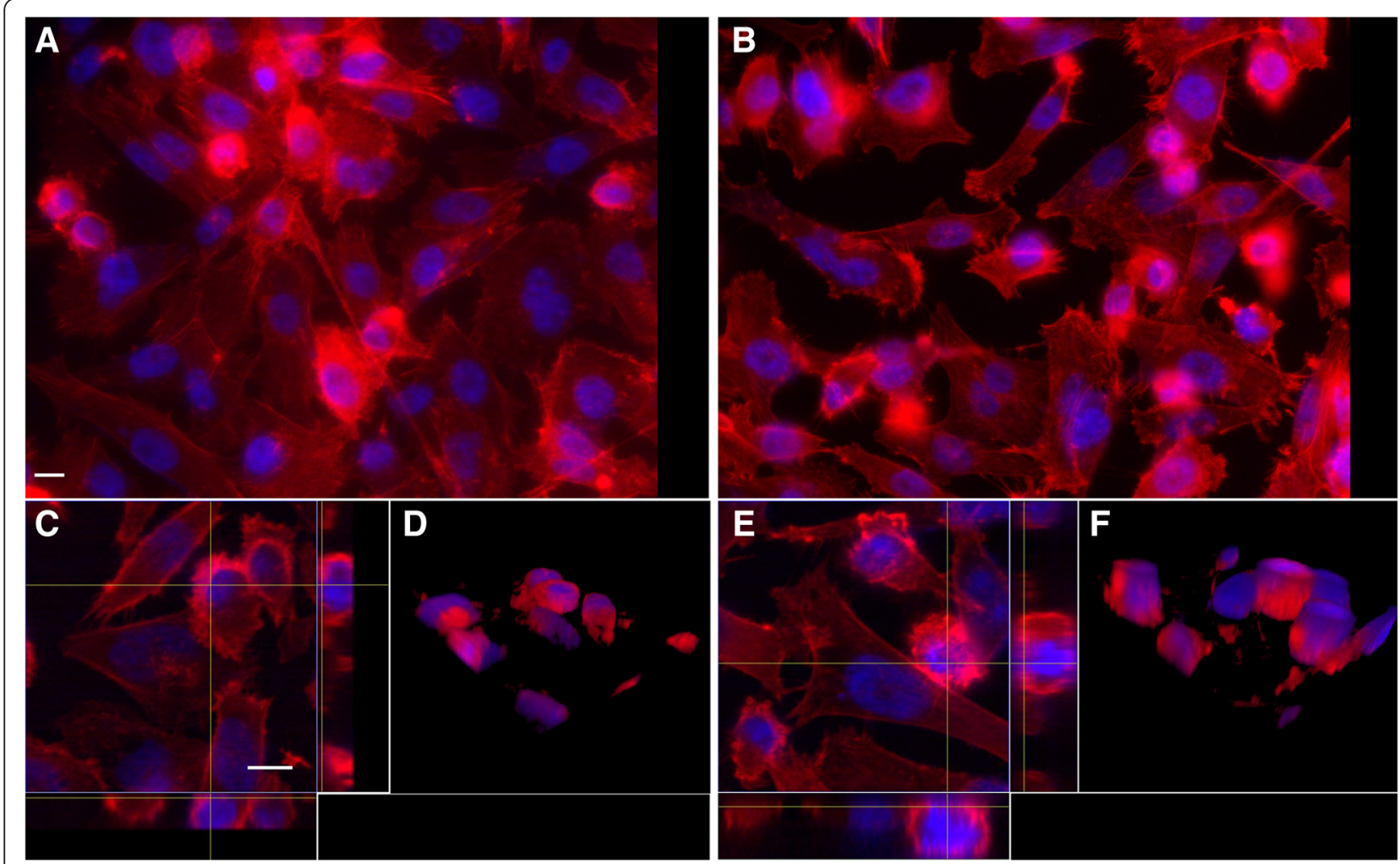

Fig. 4 Details of cell morphology changes induced by cholesterol depletion. MDA-MB 231 cells were grown for $24 \mathrm{~h}$ and treated with MbCD for $2 \mathrm{~h}$. Control (a) and treated cells (b) were stained with the F-actin probe Texas red-Phalloidin (red) and the nuclear stain Dapi (blue). To analyze the $Z$ axis of the cells in culture, stained cells were visualized with a confocal microscope. A selected slice of the $16 \mu \mathrm{m}$ stack, $1 \mu \mathrm{m}$ apart, is shown against the $Y$ and $Z$ section along the yellow line in the right and $X$ and $Z$ section in the bottom for control (c) and treated (e) cultures. Note the increase in the Z-axis in treated cells. The lateral reconstruction for the control (d) and treated cultures (f) better illustrate the increase in the Z-axis of treated cells. Scale bar in A represent $10 \mu \mathrm{m}$ in (a, b), and scale bar in C represents $10 \mu \mathrm{m}$ in $(\mathbf{c}, \mathbf{e})$

$[10,11,17,23]$. Thus, we decided to study the possible involvement of the Wnt/beta-catenin pathway in the reduction in cell migration observed after cholesterol depletion. We analyzed the effects of Wnt3a and Bio, two activators of the Wnt pathway, and Dkk-1, an inhibitor of the Wnt pathway, in the migration of MDA-MB 231 cells. Quantification of the shaved area showed that $70 \%$ of the scratched area was still empty after $24 \mathrm{~h}$ of Bio treatment, whereas cells treated with Dkk-1 covered the scratched area of the dish after $8 \mathrm{~h}$ of culture (Figs. 5 and 6). In addition, we found that only $30 \%$ of the shaved area was clear of cells after $24 \mathrm{~h}$ of Wnt3a treatment (Fig. 6). Interestingly, when added together, Dkk-1 could rescue part of the inhibitory effects of $\mathrm{MbCD}$ in cell migration (Fig. 6). These results suggest that the inhibition of MDA-MB 231 cell migration caused by MbCD-induced cholesterol depletion is, at least partially, mediated by the Wnt pathway.

Our results show a minor inhibition of Wnt3a in the migration of MDA-MB 231 cells. In contrast to our data, Matsuda and colleagues [24] described that Wnt3a increased the migratory ability of MDA-MB 231 cells in a wound closure assay. The apparent discrepancy between our results and theirs could be attributed to their lack of use of an anti-mitotic reagent (such as cytosine arabinoside or mitomycin) to inhibit cell proliferation in the wound closure assay. Wnt3a molecules have been shown to have a proliferative role in many different cell types and tissues [25]. Thus, the increased migratory ability of MDA-MB 231 cells after exposure to Wnt3a observed by Matsuda et al. [24] could be explained by an increase in cell proliferation and not cell motility.

Since we found that the effect on migratory behavior induced by $\mathrm{MbCD}$ treatment was similar to Bio (activator of the Wnt pathway) and quite different from Dkk-1 (inhibitor of the Wnt pathway), and that Dkk-1 together with $\mathrm{MbCD}$ could rescue part of the MbCD effects on cell migration, we decided to observe the ability of $\mathrm{MbCD}$ treatment to modulate the canonical Wnt/beta-catenin pathway. To test this hypothesis we analyzed the effects of $\mathrm{MbCD}$, Bio and Wnt3a on Lef-1/TCF reporter activation in permanently transfected MDA-MB 231 cells. Figure 7 shows significant Lef-1-responsive transcription of cells treated with Wnt3a and Bio, but not with $\mathrm{MbCD}$, which luciferase activity values were similar to untreated cells 


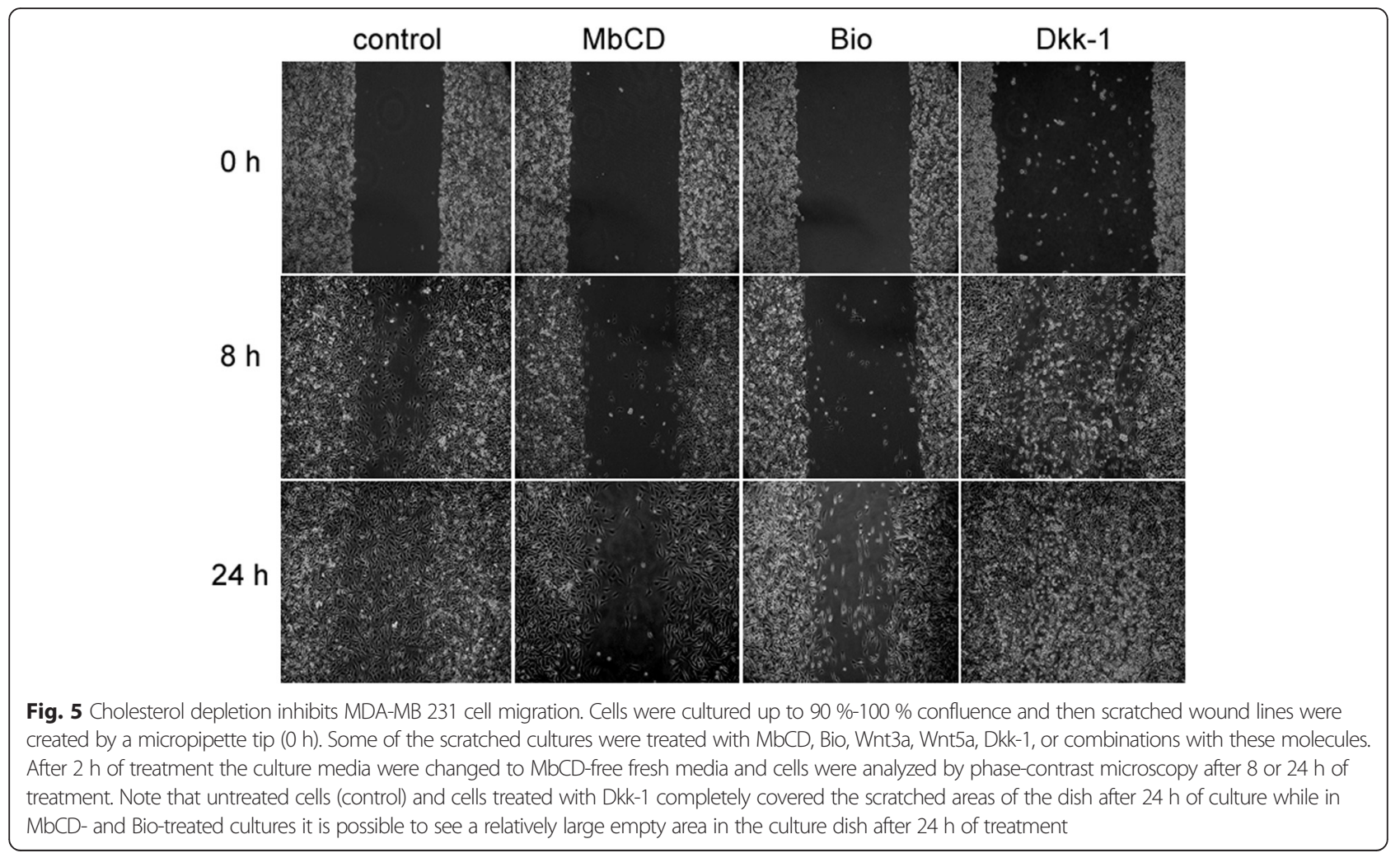

(control). These observations show that cholesterol depletion by MbCD do not activate the canonical Wnt/beta-catenin pathway in MBA-MB 231 cells.

Interestingly, quantification of the shaved area after $24 \mathrm{~h}$ of Wnt5a treatment showed the same extent of cell migration as obtained for $\mathrm{MbCD}$ (Fig. 6), suggesting that $\mathrm{MbCD}$ could be acting by a non-canonical Wnt pathway. The results with Wnt5a (Fig. 6) together with data showing that the canonical Wnt/beta-catenin pathway is not involved
(Fig. 7), lead us to hypothesize that the non-canonical Wnt pathway could be involved in the inhibition of cell migration observed after $\mathrm{MbCD}$ treatment.

Wnt5a activates the beta-catenin-independent Wnt pathway, in which small G proteins, such as Rac and Rho, and protein kinases, such as protein kinase $C$ (PKC) and $\mathrm{Ca}^{2+} /$ calmodulin-dependent kinase (CaMK), are involved [26]. The beta-catenin-independent pathway is thought to regulate the cytoskeleton, thereby

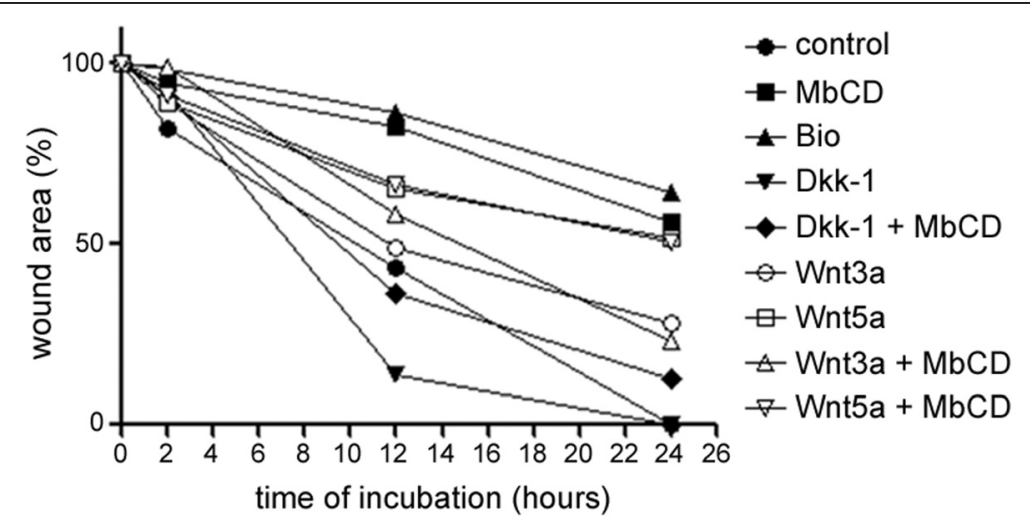

Fig. 6 Cell migration is inhibited in a similar extent with MbCD and Bio, but not with Dkk-1. Cells were cultured up to $90 \%-100 \%$ confluence and then scratched wound lines were created by a micropipette tip $(0 \mathrm{~h})$. Some of the scratched cultures were treated with MbCD, Bio, Wnt3a, Wnt5a, Dkk-1, or combinations with these molecules. After $2 \mathrm{~h}$ of treatment with MbCD the culture media was changed to MbCD-free fresh media. Wound areas were quantified after 2, 12 and $24 \mathrm{~h}$ in each condition. Note that $60 \%$ of the scratched area was still empty after $24 \mathrm{~h}$ of MbCD treatment, while cells treated with Dkk-1 completely covered the scratched areas at the same time point. Each point represents the mean of 3 independent experiments 


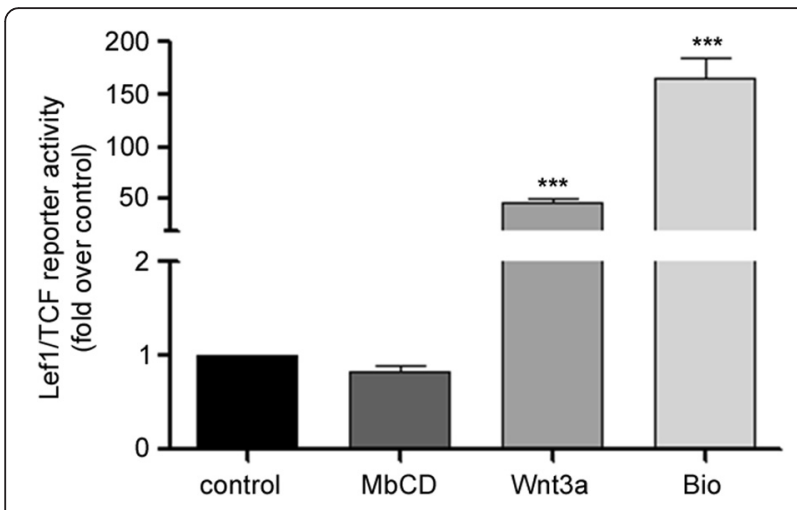

Fig. 7 Cholesterol depletion does not activate the canonical Wnt/ beta-catenin pathway. Lef-1-responsive transcription was accessed by quantifying luciferase activity after treating Lef1-TCF-luciferase reporter stably expressing MDA-MB 231 cells with 2 mM MbCD, Bio or Wnt3a for $24 \mathrm{~h}$. Note the significant Lef-1-responsive transcription of cells treated with Wnt3a and Bio, but not with MbCD, which luciferase activity values were similar to untreated cells (control). Each bar represents the mean and standard error of 3 independent experiments. ${ }^{* *} p<0.001$; ANOVA versus control group

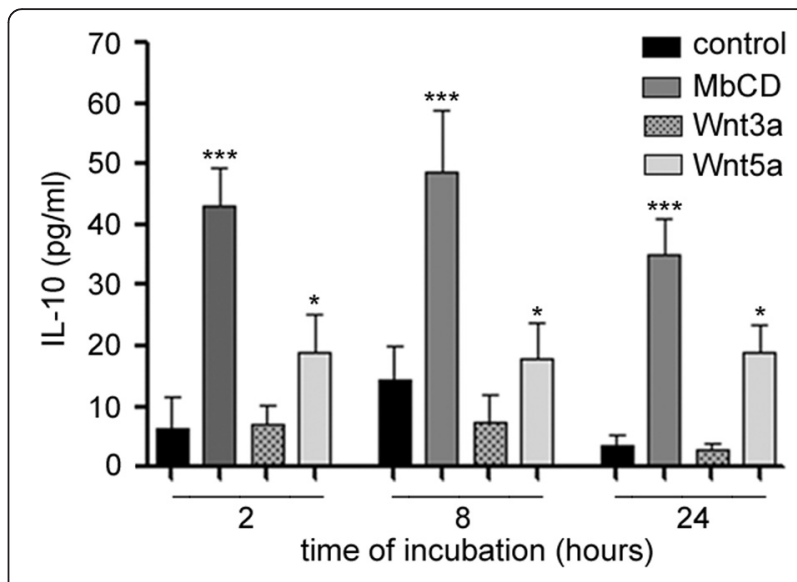

Fig. 8 Cholesterol depletion enhances the levels of IL-10 in the cultured media. IL-10 levels in conditioned media were measured by ELISA revealing significantly higher levels of $\mathrm{LL}-10$ in conditioned media collected from 2 to $24 \mathrm{~h}$ after MbCD and Wnt5a treatment, when compared to untreated cultures ( $0 \mathrm{~h})$. All samples were analyzed in triplicate and results of cytokine concentration were expressed in $\mathrm{pg} / \mathrm{mL}$ and were mean and standard error of three different experiments. ${ }^{*} p<0.05$ and ${ }^{* * *} p<0.001$; ANOVA versus control group (0 h) coordinating cell migration and polarity. Our data showing changes in the distribution of the actin cytoskeleton (Figs. 3 and 4), in cell polarity (Figs. 3 and 4) and in cell migration (Figs. 5 and 6) after cholesterol depletion is in agreement with the expected role of Wnt5a.

It has been shown that Wnt5a, but not Wnt3a, induces an increase in cytokine IL-10 production and secretion in different cell types, such as mouse dendritic cells and human macrophages [27, 28]. In addition, it has been shown that IL-10 plays an inhibitory role in epithelial cell migration [29]. So, we decided to analyze the presence of IL-10 in the conditioned media after cholesterol depletion and its possible involvement in the inhibition of cell migration observed after MbCD treatment. Interestingly, we found a significant increase in the levels of the IL-10 in conditioned media collected 2, 8 and $24 \mathrm{~h}$ after MbCD treatment (Fig. 8). These results are in agreement with our data results showing a significant increase in the amount of proteins present in the conditioned media collected after MbCD treatment (Fig. 2). We also analyzed the effects of Wnt3a and Wnt5a in the secretion of IL-10. In agreement with previous reports [27, 28], Wnt5a induced a significant increase in IL-10 levels after 2, 8 and $24 \mathrm{~h}$ of treatment, while Wnt3a did not induce IL-10 secretion (Fig. 8). The increase in IL-10 levels after cholesterol depletion and after Wnt5a treatment strengths our hypothesis that the non-canonical Wnt pathway is involved in the inhibition of cell migration observed after MbCD treatment. Supporting these data, it has been shown that IL-10 suppresses tumor metastasis of human melanoma cells [30].
We can suggest that the inhibition of MDA-MB 231 cell migration induced by cholesterol depletion might be mediated by Wnt5a and subsequent IL-10 secretion.

The collection of our results suggests the involvement of membrane cholesterol in the control of protein secretion that in turns regulates breast tumor cell migration. How membrane cholesterol controls protein secretion is not known. It has been shown that cholesterol depletion by MbCD facilitates both redistribution of SNAP25 (synaptosome-associated protein of $25 \mathrm{kDa}$ ) and sequential exocytosis [31]. SNAP25 is a component of the SNARE complex, which is involved in membrane fusion during exocytosis. The authors hypothesized that cholesterol depletion may facilitate the diffusion of SNAP25 protein along the plasma membrane and thereby enhance the redistribution of SNAP25 into fused granules or that alternatively cholesterol depletion may alter properties of the fusion pore. Interestingly, SNAP-25 is anchored to the cytosolic face of membranes via palmitoyl side chains and many effects of palmitoylation on modified proteins are thought to reflect changes in association with cholesterolrich membrane domains [32, 33].

We have previously shown that cholesterol depletion induces the release of Wnt molecules to the culture medium in primary cultures of myoblast cells $[10,11]$. Several Wnt proteins (such as Wnt-5a) are palmitoylated and palmitoylated proteins are frequently targeted to cholesterol-enriched membrane domains. Thus, in face of our results we postulate that depletion of membrane cholesterol could alter Wnt availability and release. 


\section{Conclusions}

Here we show for the first time a correlation between membrane cholesterol, non-canonical Wnt signaling, IL10 secretion and breast tumor cell migration. Our results show that membrane cholesterol depletion reduces cell migration, induces changes in cell morphology and in membrane protrusions. Cholesterol depletion also induces an increase in the secretion of IL-10. In addition, we show that Wnt5a inhibited cell migration in similar levels as $\mathrm{MbCD}$, pointing to a role for the non-canonical Wnt pathway and IL-10 in this process. These results could contribute to the understanding of breast tumor cell migration and may be used in the development of new therapeutic strategies targeted to breast cancer metastasis.

\section{Acknowledgments}

The authors thank Juliana Lourenço and Alan Minho for their expert technical assistance. This work was supported by Brazilian grants from Conselho Nacional de Desenvolvimento Científico e Tecnológico (CNPq), Fundação Carlos Chagas Filho de Apoio à Pesquisa do Estado do Rio de Janeiro (FAPERJ), Coordenação de Aperfeiçoamento de Pessoal de Nível Superior (CAPES) and Fundação do Câncer/Programa de Oncobiologia.

\section{Authors' contributions}

FSG carried out the cell cultures, immunofluorescence, ELISA and cell viability experiments. LSS carried out the cholesterol determination assays. MB carried out the electroporations. MIDR and SK participated in the luciferase reporter experiments. MLC participated in image analysis and in the interpretation of data. CM and PF conceived the study, participated in its design, in the interpretation of data, coordination of the study and in the writing of the manuscript. All authors read and approved the final version of the manuscript.

\section{Competing interest}

The authors declare that they have no conflicts of interest.

\section{Author details}

${ }^{1}$ Instituto de Ciências Biomédicas, Universidade Federal do Rio de Janeiro, Rio de Janeiro, RJ 21941-902, Brazil. ${ }^{2}$ Instituto de Biofísica Carlos Chagas Filho, Universidade Federal do Rio de Janeiro, Rio de Janeiro, Brazil. ${ }^{3}$ Instituto Nacional de Câncer, Programa de Carcinogênese Molecular, Rio de Janeiro, Brazil. ${ }^{4}$ Fundação Instituto Oswaldo Cruz, Vice-presidência de Pesquisa e Laboratórios de Referência, Rio de Janeiro, Brazil.

\section{Received: 12 January 2016 Accepted: 5 August 2016}

Published online: 30 August 2016

\section{References}

1. Dessi S, Batetta B, Pulisci D, Spano O, Anchisi C, Tessitore L, Costelli P, Baccino FM, Aroasio E, Pani P. Cholesterol content in tumor tissues is inversely associated with high-density lipoprotein cholesterol in serum in patients with gastrointestinal cancer. Cancer. 1994;73:253-8.

2. Freeman MR, Solomon KR. Cholesterol and prostate cancer. J Cell Biochem. 2004;91:54-69

3. Kolanjiappan K, Ramachandran CR, Manoharan S. Biochemical changes in tumor tissues of oral cancer patients. Clin Biochem. 2003:36:61-5.

4. Tosi MR, Bottura G, Lucchi P, Reggiani A, Trinchero A, Tugnoli V. Cholesteryl esters in human malignant neoplasms. Int J Mol Med. 2003;11:95-8.

5. Tosi MR, Tugnoli V. Cholesteryl esters in malignancy. Clin Chim Acta. 2005; 359:27-45.

6. Krycer JR, Brown AJ. Cholesterol accumulation in prostate cancer: A classic observation from a modern perspective. Biochim Biophys Acta. 1835;2013: 219-29.

7. Maxfield FR, Tabas I. Role of cholesterol and lipid organization in disease Nature. 2005:438:612-21.

8. Ohtani Y, Irie T, Uekama K, Fukunaga K, Pitha J. Differential effects of alpha-, beta- and gamma-cyclodextrins on human erythrocytes. Eur J Biochem. 1989;186:17-22.
9. Zidovetzki R, Levitan I. Use of cyclodextrins to manipulate plasma membrane cholesterol content: evidence, misconceptions and control strategies. Biochim Biophys Acta. 2007;1768:1311-24.

10. Mermelstein CS, Portilho DM, Mendes FA, Costa ML, Abreu JG. Wnt/betacatenin pathway activation and myogenic differentiation are induced by cholesterol depletion. Differentiation. 2007;75:184-92.

11. Portilho DM, Martins ER, Costa ML, Mermelstein CS. A soluble and active form of Wnt-3a protein is involved in myogenic differentiation after cholesterol depletion. FEBS Lett. 2007:581:5787-95.

12. Courchaine AJ, Miller WH, Stein DBJ. Rapid semimicro procedure for estimating free and total cholesterol. Clin Chem. 1959:5:609-14.

13. Chicaybam L, Sodre AL, Curzio BA, Bonamino MH. An efficient low cost method for gene transfer to T lymphocytes. PLoS One. 2013;8:e60298.

14. Fuerer C, Nusse R. Lentiviral vectors to probe and manipulate the Wnt signaling pathway. PLoS One. 2010;5:e9370.

15. Christian AE, Haynes MP, Phillips MC, Rothblat GH. Use of cyclodextrins for manipulating cellular cholesterol content. J Lipid Res. 1997;38:2264-72.

16. Onodera R, Motoyama K, Okamatsu A, Higashi T, Kariya R, Okada S, Arima H. Involvement of cholesterol depletion from lipid rafts in apoptosis induced by methyl- $\beta$-cyclodextrin. Int J Pharm. 2013:452:116-23.

17. Mermelstein CS, Portilho DM, Medeiros RB, Matos AR, Einicker-Lamas M, Tortelote GG, Vieyra A, Costa ML. Cholesterol depletion by methyl- $\beta$ cyclodextrin enhances myoblast fusion and induces the formation of myotubes with disorganized nuclei. Cell Tissue Res. 2005;319:289-97.

18. Pontes Soares C, Portilho DM, Da Silva SL, Einicker-Lamas M, Morales MM, Costa ML, dos Santos Mermelstein C. Membrane cholesterol depletion by methyl-beta-cyclodextrin enhances the expression of cardiac differentiation markers. Cells Tissues Organs. 2010;192:187-99.

19. Awad $A B$, Williams $H$, Fink CS. Phytosterols reduce in vitro metastatic ability of MDA-MB-231 human breast cancer cells. Nutr Cancer. 2001:40:157-64.

20. Danilo C, Gutierrez-Pajares JL, Mainieri MA, Mercier I, Lisanti MP, Frank PG. Scavenger receptor class B type I regulates cellular cholesterol metabolism and cell signaling associated with breast cancer development. Breast Cancer Res. 2013;15:R87.

21. Antalis CJ, Uchida A, Buhman KK, Siddiqui RA. Migration of MDA-MB-23 breast cancer cells depends on the availability of exogenous lipids and cholesterol esterification. Clin Exp Metastasis. 2011:28:733-41.

22. Raghu H, Sodadasu PK, Malla RR, Gondi CS, Estes N, Rao JS. Localization of UPAR and MMP-9 in lipid rafts is critical for migration, invasion and angiogenesis in human breast cancer cells. BMC Cancer. 2010;10:647.

23. Portilho DM, Soares CP, Morrot A, Thiago LS, Butler-Browne G, Savino W, Costa ML, Mermelstein C. Cholesterol depletion by methyl- $\beta$-cyclodextrin enhances cell proliferation and increases the number of desmin-positive cells in myoblast cultures. Eur J Pharmacol. 2012;694:1-12.

24. Matsuda Y, Schlange T, Oakeley EJ, Boulay A, Hynes NE. WNT signaling enhances breast cancer cell motility and blockade of the WNT pathway by sFRP1 suppresses MDA-MB-231 xenograft growth. Breast Cancer Res. 2009;11:R32.

25. Galli LM, Willert K, Nusse R, Yablonka-Reuveni Z, Nohno T, Denetclaw W, Burrus LW. A proliferative role for Wnt-3a in chick somites. Dev Biol. 2004;269:489-504.

26. Veeman MT, Axelrod JD, Moon RT. A second canon. Functions and mechanisms of beta-catenin-independent Wht signaling. Dev Cell. 2003;5:367-77.

27. Bergenfelz C, Medrek C, Ekström E, Jirström K, Janols H, Wullt M, Bredberg A, Leandersson K. Wnt5a induces a tolerogenic phenotype of macrophages in sepsis and breast cancer patients. J Immunol. 2012;188:5448-58.

28. Oderup C, LaJevic M, Butcher EC. Canonical and noncanonical Wnt proteins program dendritic cell responses for tolerance. J Immunol. 2013;190:6126-34.

29. Wang B, Zhuang L, Fujisawa H, Shinder GA, Feliciani C, Shivji GM, Suzuki H, Amerio P, Toto P, Sauder DN. Enhanced Epidermal Langerhans Cell Migration in IL-10 Knockout Mice. J Immunol. 1999;162:277-83.

30. Huang S, Xie K, Bucana CD, Ullrich SE, Bar-Eli M. Interleukin 10 suppresses tumor growth and metastasis of human melanoma cells: potential inhibition of angiogenesis. Clin Cancer Res. 1996;2:1969-79.

31. Takahashi N, Hatakeyama H, Okado H, Miwa A, Kishimoto T, Kojima T, Abe T, Kasai $\mathrm{H}$. Sequential exocytosis of insulin granules is associated with redistribution of SNAP25. J Cell Biol. 2004;165:255-62.

32. Greaves J, Chamberlain LH. Palmitoylation-dependent protein sorting. J Cell Biol. 2007;176:249-54.

33. Melkonian KA, Ostermeyer AG, Chen JZ, Roth MG, Brown DA. Role of lipid modifications in targeting proteins to detergent-resistant membrane rafts. Many raft proteins are acylated, while few are prenylated. J Biol Chem. 1999; 274:3910-7. 